\title{
BMJ Open Short-term postoperative outcomes of colorectal cancer among patients with chronic liver disease: a national population-based study
}

\author{
Ko-Chao Lee, ${ }^{1}$ Kuan-Chih Chung, ${ }^{2}$ Hong-Hwa Chen, ${ }^{1}$ Kung-Chuan Cheng, ${ }^{1}$ \\ Kuen-Lin Wu, ${ }^{1}$ Chien-Chang Lu ${ }^{1}$
}

To cite: Lee K-C, Chung K-C, Chen $\mathrm{H}-\mathrm{H}$, et al. Short-term postoperative outcomes of colorectal cancer among patients with chronic liver disease: a national populationbased study. BMJ Open 2018;8:e020511. doi:10.1136/ bmjopen-2017-020511

- Prepublication history for this paper is available online. To view these files, please visit the journal online (http://dx.doi. org/10.1136/bmjopen-2017020511).

$\mathrm{K}-\mathrm{CL}$ and $\mathrm{K}-\mathrm{CC}$ contributed equally.

Received 8 November 2017 Revised 23 May 2018 Accepted 26 June 2018

Check for updates

(c) Author(s) (or their employer(s)) 2018. Re-use permitted under CC BY-NC. No commercial re-use. See rights and permissions. Published by BMJ.

${ }^{1}$ Division of Colorectal Surgery, Department of Surgery, Chang Gung Memorial Hospital -

Kaohsiung Medical Center

Chang Gung University College of Medicine, Kaohsiung, Taiwan ${ }^{2}$ Department of Anesthesiology, Chang Gung Memorial Hospital - Kaohsiung Medical Center, Chang Gung University College of Medicine, Kaohsiung, Taiwan

Correspondence to

Dr Ko-Chao Lee;

kmch4329@gmail.com

\section{ABSTRACT}

Objective Patients with colorectal carcinoma (CRC) with pre-existing chronic liver disease (CLD) had a significantly higher 30-day mortality after CRC surgery compared with healthy controls. This study investigated the factors associated with postoperative complications and inhospital mortality in patients with CRC with coexisting CLD (excluding cirrhosis) who underwent colorectal surgery.

Design A retrospective, observational, population-based study.

Setting Data were sourced from the National Inpatient Sample database, a part of the Healthcare Cost and Utilisation Project.

Participants This study analysed 7463 inpatients with CRC who underwent colorectal surgery on admission between 2005 and 2014.

Primary and secondary outcome measures The primary endpoint of this study was the prevalence of postoperative complications, and the secondary endpoint was in-hospital mortality.

Results In the CLD group, $36.27 \%$ of patients had chronic hepatitis C, $28.36 \%$ had non-alcoholic fatty liver disease and $31.19 \%$ had other types of CLD. The median hospital stay was $7.0(5.0-10.0)$ days in patients with no postoperative complications vs $17.0(10.0-26.0)$ days, $8.0(6.0-12.0)$ days, $8.0(6.0-17.0)$ days, 9.0 (8.0-14.0) days and 10.5 (7.0-17.0) days for patients with postoperative infection, postoperative bleeding, cardiac arrest/heart failure, respiratory complications and digestive complications, respectively (all $p<0.05$ ). The presence of CLD was significantly associated with higher risk of postoperative bleeding (adjusted OR $(\mathrm{aOR})=1.64$, $95 \% \mathrm{Cl} 1.15$ to $2.34, \mathrm{p}=0.007)$. The presence of CLD (aOR=1.98, 95\% Cl 1.39 to $2.82, \mathrm{p}<0.001$ ) and length of hospital stay $(\mathrm{aOR}=1.06,95 \% \mathrm{Cl} 1.04$ to $1.08, \mathrm{p}<0.001)$ were significantly associated with higher risk of in-hospital mortality. However, hyperlipidaemia was associated with a significantly lower risk of mortality $(\mathrm{aOR}=0.46,95 \% \mathrm{Cl}$ 0.28 to $0.75, p=0.002$ ).

Conclusions Postoperative complications prolonged the length of hospital stay. The presence of CLD and hyperlipidaemia were important factors impacting postoperative complications and in-hospital mortality in patients with CRC with underlying CLD.
Strengths and limitations of this study

Data for this study were collected from a large, comprehensive and national representative database.

- A large multiethnic population sample allowed us to explore racial/ethnic heterogeneity.

- The cross-sectional design of this study can only demonstrate association; therefore, causality could not be determined.

\section{INTRODUCTION}

Colorectal cancer (CRC) is the most common gastrointestinal malignancy and the second leading cause of cancer-related deaths in developed countries, accounting for 51690 deaths in the USA in 2012. ${ }^{12}$ The 5-year survival rates range from $90 \%$ for cancers detected at the localised stage, $70 \%$ for regional tumours and $10 \%$ for distant metastatic tumours. ${ }^{3}$ The major risk factors of CRC include age and hereditary factors, the presence of inflammatory bowel disease, and environmental factors such as nutritional practices, physical activity/obesity, cigarette smoking and alcohol consumption. ${ }^{4}$ The implementation of population-based screening for average-risk, asymptomatic individuals beginning at 50 years of age has resulted in a significant decrease in CRC incidence among individuals $>50$ years old. Patients with CRC who present at an early stage usually receive curative surgical resection, whereas patients who present with metastatic disease receive palliative systemic chemotherapy or treatment with novel biologic agents. ${ }^{5}$

Chronic liver disease (CLD) represents a major health concern and accounts for approximately 1 million deaths per year worldwide. ${ }^{6}$ The major risk factors for CLD include chronic viral hepatitis infection, chronic exposure to toxins (including excessive alcohol consumption) and autoimmune 
injury, which all contribute towards progression of hepatic fibrosis and development of cirrhosis via the production and deposition of extracellular matrix components. ${ }^{7}$ CLD also includes liver damage mediated by lipid accumulation in the hepatocytes. The spectrum of obesity-related liver disease such as non-alcoholic fatty liver disease (NAFLD) can range from non-alcoholic steatohepatitis with inflammation and fibrosis, and end in cirrhosis. ${ }^{8}$

Patients with liver disease who had CRC frequently required surgery and anaesthesia, and were shown to have an increased risk of perioperative complications and postoperative morbidity and mortality. This could be due to complications associated with liver disease, including hepatic encephalopathy, ascites, sepsis and haemorrhage. ${ }^{9}$ Patients with mild to moderate CLD without cirrhosis usually tolerate surgery well, whereas acute liver failure (previously termed fulminant hepatic failure) and acute viral or alcoholic hepatitis are considered contraindications to elective surgery. ${ }^{10}$ Additionally, it has been reported that the location of the surgical procedure is an important risk factor for postoperative liver failure in patients with pre-existing liver disease. Cardiac surgery, abdominal surgery and hepatic resection are all associated with higher rates of perioperative complications, and higher rates of morbidity and mortality, compared with more peripheral surgery, presumably due to greater reductions in hepatic blood flow. ${ }^{11}$

A recent meta-analysis of 50 studies reported that patients with CLD had a significantly higher risk of CRC, which persisted after liver transplantation, compared with the general population. ${ }^{12}$ Patients with CRC with pre-existing liver disease were shown to have a significantly higher 30-day mortality after CRC surgery compared with patients with CRC with non-cirrhotic liver disease and healthy controls. ${ }^{13}$ Other data showed that colectomy of any kind was associated with a significant risk of postoperative morbidity and mortality in patients with cirrhosis, ${ }^{14}$ and this was thought to be related to increased intraoperative and early postoperative bleeding. ${ }^{15}$ Additionally, although fatty liver has been shown to be an important risk factor of CRC, ${ }^{16}$ the presence of NAFLD is thought to play a protective role in the overall survival of patients with CRC. ${ }^{17}$

The aim of our present study was to identify the risk factors associated with postoperative complications and mortality in patients with CRC with coexisting CLD who underwent colorectal surgery. Our clinical data were sourced from a national and comprehensive database, which made it possible to minimise discrepancies and biases.

\section{METHODS}

\section{Data source}

In this population-based, cross-sectional study, data were sourced from the National Inpatient Sample (NIS) database, which is part of the Healthcare Cost and Utilization Project (HCUP). The NIS database samples approximately $20 \%$ of discharges from all HCUP participating community hospitals and is the largest publicly available inpatient database in the USA (www.hcup-us. ahrq.gov/nisoverview.jsp). The NIS is representative of approximately $95 \%$ of the US population (http://www. cdc.gov/nchs/nhanes/). All of the HCUP-NIS data are de-identified.

\section{Study population}

This study extracted data of inpatients diagnosed with primary CRC based on specific International Classification of Diseases, 9th Revision, Clinical Modification (ICD-9-CM) codes $(153,154)$ who underwent surgical intervention on admission. Surgical interventions included open and partial or subtotal colectomy (ICD-9-CM: 45.7), pull-through resection of the rectum (ICD-9-CM: 48.40, 48.41, 48.43, 48.49), abdominoperineal resection of the rectum/complete proctectomy (ICD-9-CM: 48.50, 48.52, 48.59) and other resections of the rectum/partial proctectomy/rectosigmoidectomy (ICD-9-CM: 48.6x). Patients with missing data on demographics, patients diagnosed with liver cirrhosis and patients with coexisting other primary malignancies were excluded.

\section{Study variables}

The primary endpoint of this study was the prevalence of postoperative complications, including postoperative infection (ICD-9-CM: 998.5), postoperative shock (ICD-9-CM: 998.0), postoperative bleeding (ICD-9-CM:998.1), disruption of wound (ICD-9-CM:998.3), non-healing surgical wound (ICD-9-CM: 998.83), nervous system complications (ICD-9-CM: 997.0x), cardiac arrest/heart failure (ICD-9-CM: 997.1), phlebitis/thrombophlebitis (ICD-9-CM: 997.2), respiratory complications (ICD-9-CM: 997.3x), digestive system complications (ICD-9-CM: 997.4), urinary complications (ICD-9-CM: 997.5), vascular complications (ICD-9-CM: 997.7x) and unspecified complications (ICD-9-CM: 998.9). The secondary endpoint was in-hospital mortality, which reflected the severity of the disease.

The independent variables included the presence of CLD. Although there were several aetiologies of CLD, we only focused on specific aetiologies found in higher percentages in our study population, such as chronic hepatitis B (ICD-9-CM: 070.22, 070.32), chronic hepatitis C (ICD-9-CM: 070.44, 070.54, 070.7x), NAFLD (ICD-9-CM: 571.8, 571.9) and other minor causes.

The relative variables obtained from each record included patient demographics (age, gender, race/ ethnicity), socioeconomic status (SES) (household income), severity of CRC (locoregional involvement, distant metastasis), comorbidity (hyperlipidaemia, obesity), place of hospitalisation, type of admission (elective, non-elective) and length of hospital stay.

\section{SES: household income}

This categorical variable provides a quartile classification of the estimated median household income of residents 
in the patient's Zip code. The quartiles are identified by values of $1-4$, indicating the poorest to wealthiest populations. These values are derived from Zip code-demographic data obtained from Claritas. Since these estimates are updated annually, the ranges of value for these categories vary by year.

\section{Comorbidities}

For matching the criteria between the case and control groups, a number of comorbid conditions were included, such as diabetes, hypertension, cardiovascular disease, congestive heart failure, cerebrovascular disease, Alzheimer's disease and other cognitive impairment, AIDS, alcohol abuse, chronic blood loss anaemia, chronic pulmonary disease, coagulopathy, drug abuse, hypothyroidism, other neurological disorders, peripheral vascular disorders, pulmonary circulation disorders, renal failure, valvular diseases, and weight loss.

For relative variables, two comorbid conditions (hyperlipidaemia and obesity) were selected to be incorporated into the analysis. These two conditions were intercorrelated and were selected considering the difficulty of operation in obese patients, which could cause a series of postoperative complications.

\section{Patient and public involvement}

Since the present study used the NIS database, which is the largest publicly available inpatient healthcare database in the USA, there is no patient and public involvement.

\section{Statistical analysis}

Simple matching was used to match inpatients who had CLD with those who did not have CLD by age, gender, severity of CRC and comorbidities. Selected cases were matched with controls by 1:4 matching. Continuous variables were expressed as mean $\pm \mathrm{SD}$, and categorical data were shown as counts and percentages. Conditional logistic regression method was performed after matching, and a univariate logistic regression model was performed to determine the independent risk factors of postoperative complications or mortality. Multiple logistic regression analysis was performed on variables with an unadjusted effect and a p value $<0.05$ on univariate logistic regression analysis. Statistical significance was defined by a $p$ value $<0.05$. Statistical analyses were performed using the SAS V.9.4 software.

\section{RESULTS}

\section{Patient demographics and clinical characteristics}

Analysis of the HCUP-NIS database for the period 20052014 showed that 152625 inpatients diagnosed with CRC had undergone surgical treatment. After excluding patients with liver cirrhosis, patients with coexisting other primary malignancies and patients with missing data for age and gender, a total of 129958 inpatients were enrolled in this study. The study population comprised 1555 patients with CLD (case group) and 128403 patients without CLD (control group). Due to the small sample size of the case group, simple matching was used to balance the case and control groups. After matching, a total of 7463 inpatients were enrolled in the final study population. Of these patients, 5908 patients $(79.16 \%)$ had no CLD and 1555 patients (20.84\%) had CLD. Majority of patients in the CLD group had chronic hepatitis C ( $\mathrm{n}=564,36.27 \%)$, while $441(28.36 \%)$ patients had NAFLD and 485 (31.19\%) patients had other types of CLD.

The baseline demographics and clinical characteristics of the study patients are described in table 1 . The mean age of the inpatients was 62.53 years old, and the mean length of hospital stay was 8.96 days. Majority of the inpatients $(57.39 \%)$ were male, and $60.78 \%$ were white. A total of 1993 patients (26.71\%) were classified into the first quartile of the median household income, and almost half of the patients (49.99\%) were operated on in urban teaching hospitals.

Analysis of the whole study population showed that 1633 inpatients $(21.88 \%)$ had postoperative complications, the most frequent of which was digestive system complications $(\mathrm{n}=675,41.33 \%)$. A total of 1839 patients (24.64\%) had hyperlipidaemia and 907 patients $(12.15 \%)$ were obese. The length of hospital stay was $8.61 \pm 6.49$ days for non-CLD patients and 10.26 9.46 for patients with CLD. In-hospital mortality was recorded for 162 inpatients $(2.17 \%)$.

\section{Factors associated with postoperative complications in} patients with CRC with underlying CLD

Univariate and multivariate logistic regression analyses were performed to assess the risk factors significantly associated with postoperative complications (table 2). Although univariate analysis showed that hyperlipidaemia and length of hospital stay were both significantly associated with risk of postoperative complications, the length of hospital stay was the only variable significantly associated with risk of postoperative complications by multivariate analysis $(\mathrm{aOR}=1.13,95 \%$ CI 1.12 to $1.15, \mathrm{p}<0.001)$. The presence of underlying CLD was not significantly associated with the occurrence of overall postoperative complications (adjusted OR $(\mathrm{aOR})=0.91,95 \%$ CI 0.78 to $1.05, \mathrm{p}=0.192$ ).

We subsequently used logistic regression analysis to identify factors associated with specific postoperative complications, which occurred in $>5 \%$ of patients (postoperative infection, postoperative bleeding, cardiac arrest/heart failure, respiratory complications and digestive system complications; table $3 \mathrm{~A}$, table $3 \mathrm{~B}$ and table 4 ). Univariate analysis showed that (1) the presence of hyperlipidaemia and length of hospital stay were significantly associated with postoperative infection (both $\mathrm{p}<0.010$; table 3A); (2) the presence of CLD and length of hospital stay were significantly associated with postoperative infection and postoperative bleeding (both $\mathrm{p}<0.010$; table $3 \mathrm{~A}$ ); (3) the presence of CLD, treatment at an urban teaching hospital and length of hospital stay were significantly 
Table 1 Baseline demographic and clinical characteristics of the study population

\section{Chronic liver diseases}

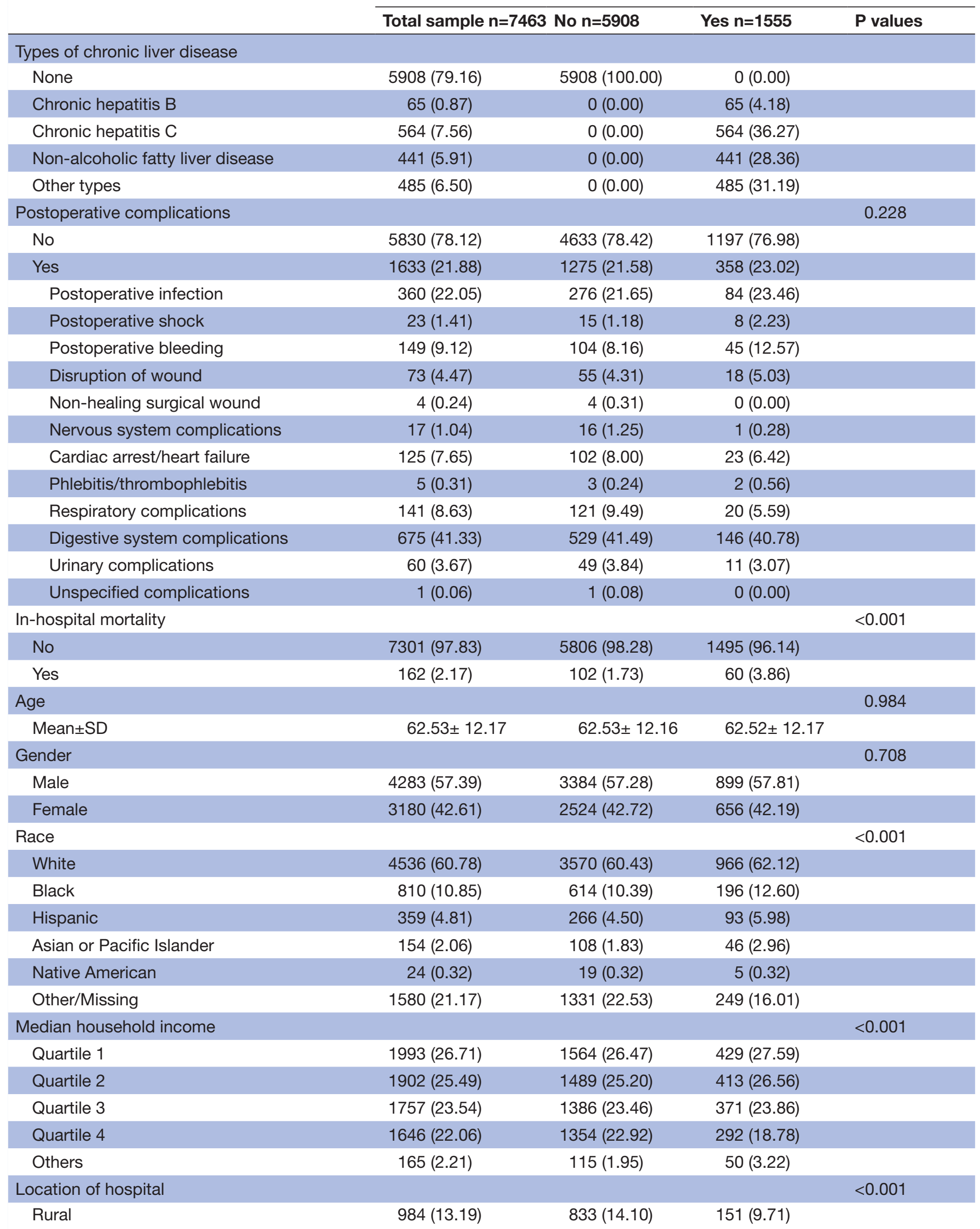




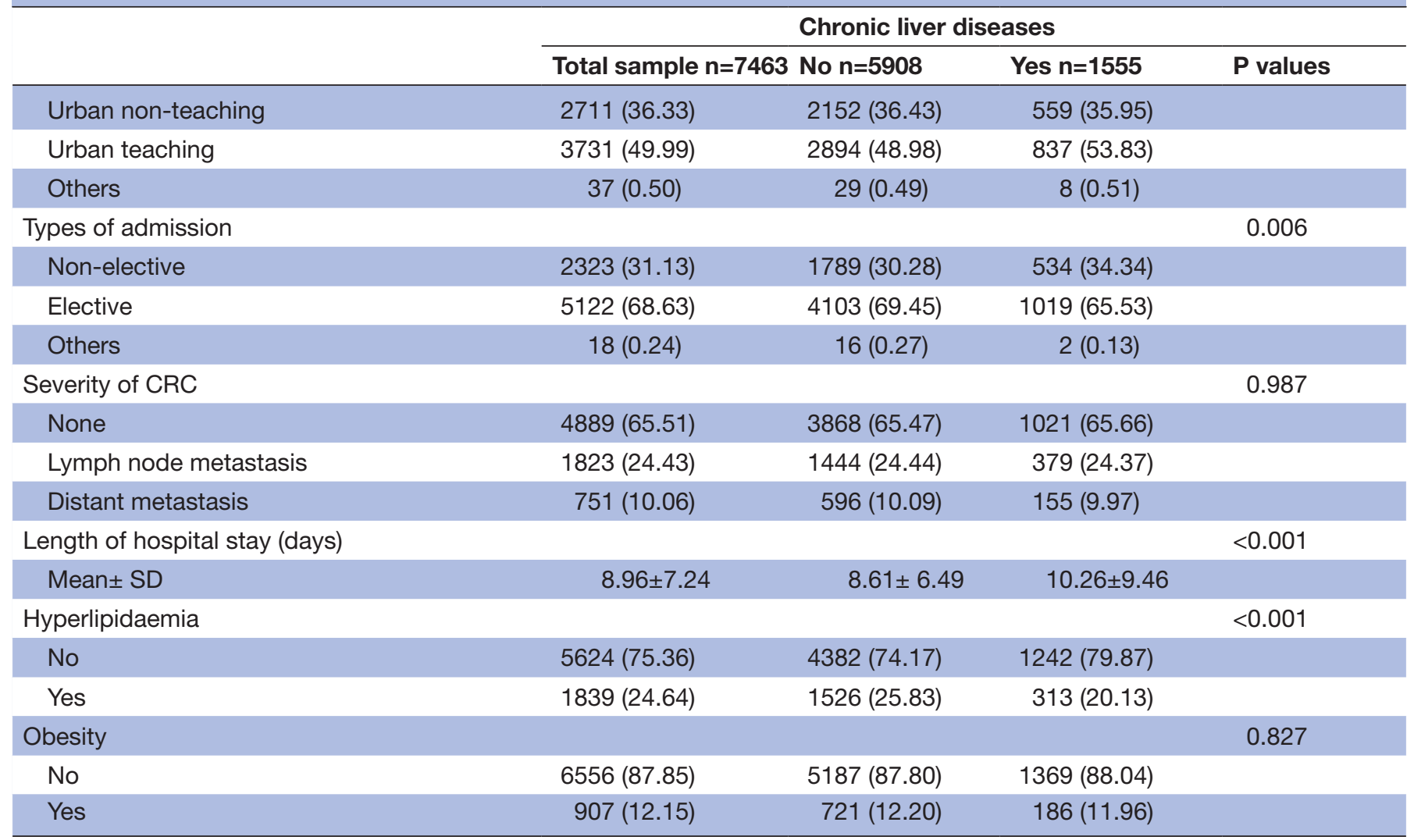

$\mathrm{CRC}$, colorectal cancer.

associated with respiratory complications (all $\mathrm{p} \leq 0.048$; table 3B); and (4) black race and length of hospital stay were both significantly associated with digestive system complications $(p<0.05$; table $3 \mathrm{~B})$. None of the factors analysed was significantly associated with cardiac arrest/ heart failure (all $\mathrm{p} \geq 0.05$; table $3 \mathrm{~A}$ ).

Our multivariate analysis showed that (1) length of hospital stay was the only factor significantly associated with postoperative infection $(\mathrm{aOR}=1.13,95 \%$ CI 1.11 to $1.15, \mathrm{p}<0.001)$ (table 4); (2) presence of CLD $(\mathrm{aOR}=1.64$, $95 \%$ CI 1.15 to $2.34, \mathrm{p}=0.007$ ) and length of hospital stay $(\mathrm{aOR}=1.02,95 \%$ CI 1.01 to $1.04, \mathrm{p}=0.013)$ were both significantly associated with postoperative bleeding; (3) patients with CLD and patients treated at an urban teaching hospital had a lower risk of respiratory complications (CLD: aOR=0.58, 95\% CI 0.36 to $0.95, \mathrm{p}=0.029$; urban teaching hospital: aOR $=0.44,95 \%$ CI 0.26 to 0.75 , $\mathrm{p}=0.002$, respectively), while length of hospital stay was positively associated with respiratory complications (aOR $=1.04,95 \%$ CI 1.02 to $1.07, \mathrm{p}<0.001)$; and (4) length of hospital stay was the only variable significantly associated with digestive system complications ( $\mathrm{aOR}=1.05,95 \%$ CI 1.04 to $1.06, \mathrm{p}<0.001$; table 4 ).

Factors associated with in-hospital mortality in inpatients with CRC with underlying CLD

Univariate and multivariate logistic regression analyses were performed to assess the risk factors significantly associated with in-hospital mortality (table 5). Compared with patients without CLD, inpatients who had CLD had a significantly higher risk of in-hospital mortality events $(\mathrm{aOR}=2.05,95 \%$ CI 1.43 to $2.94, \mathrm{p}<0.001)$. Multivariate analysis also showed that the length of hospital stay was significantly associated with in-hospital mortality events (aOR=1.06, 95\% CI 1.04 to $1.08, \mathrm{p}<0.001)$. However, patients with elective admission $(\mathrm{aOR}=0.50,95 \%$ CI 0.34 to $0.73, \mathrm{p}<0.001)$ and inpatients with hyperlipidaemia had a significantly lower risk of mortality $(\mathrm{aOR}=0.46,95 \%$ CI 0.28 to $0.75, \mathrm{p}=0.002$ ) compared with inpatients without hyperlipidaemia and inpatients without elective admission, respectively.

Postoperative complications were associated with length of hospital stay among patients with CRC with underlying CLD Since our multivariate analysis suggested that the length of hospital stay was correlated with different postoperative complications, we analysed the length of hospital stay in patients with and without postoperative complications (table 6). Patients who did not have postoperative complications had a median hospital stay of 7.0 (5.0-10.0) days. In contrast, the length of hospital stay was 17.0 (10.026.0) days, 8.0 (6.0-12.0) days, 8.0 (6.0-17.0) days, 9.0 (8.0-14.0) days and 10.5 (7.0-17.0) days in patients with postoperative infection $(\mathrm{p}<0.001)$, postoperative bleeding $(p=0.009)$, cardiac arrest/heart failure $(p=0.047)$, respiratory complications $(\mathrm{p}=0.007)$ and digestive complications $(\mathrm{p}<0.001)$, respectively. 
Table 2 Univariate and multivariate logistic regression analyses to identify factors associated with postoperative complications among inpatients diagnosed with colorectal cancer

\begin{tabular}{|c|c|c|c|c|}
\hline & \multicolumn{2}{|l|}{ Univariate } & \multicolumn{2}{|l|}{ Multivariate } \\
\hline & OR (95\% Cl) & $P$ values & Adjusted OR (95\% Cl) & $P$ values \\
\hline \multicolumn{5}{|l|}{ Chronic liver diseases } \\
\hline No & Reference & & Reference & \\
\hline Yes & 1.08 (0.94 to 1.23$)$ & 0.292 & 0.91 (0.78 to 1.05$)$ & 0.192 \\
\hline \multicolumn{5}{|l|}{ Race } \\
\hline White & Reference & & & \\
\hline Black & 1.01 (0.83 to 1.23$)$ & 0.905 & & \\
\hline Hispanic & 1.03 (0.79 to 1.35$)$ & 0.827 & & \\
\hline Asian or Pacific islander & 0.85 (0.54 to 1.34$)$ & 0.494 & & \\
\hline Native American & 1.10 (0.42 to 2.92$)$ & 0.845 & & \\
\hline Other/Missing & 0.95 (0.81 to 1.10$)$ & 0.456 & & \\
\hline \multicolumn{5}{|l|}{ Median household income } \\
\hline Quartile 1 & Reference & & & \\
\hline Quartile 2 & 1.16 (0.99 to 1.36$)$ & 0.075 & & \\
\hline Quartile 3 & 0.93 (0.79 to 1.10$)$ & 0.389 & & \\
\hline Quartile 4 & 1.02 (0.86 to 1.21$)$ & 0.827 & & \\
\hline Others & 1.06 (0.71 to 1.59$)$ & 0.785 & & \\
\hline \multicolumn{5}{|l|}{ Location of hospital } \\
\hline Rural & Reference & & & \\
\hline Urban non-teaching & 1.09 (0.90 to 1.32$)$ & 0.355 & & \\
\hline Urban teaching & 1.04 (0.87 to 1.25$)$ & 0.667 & & \\
\hline Others & 1.25 (0.57 to 2.75$)$ & 0.572 & & \\
\hline \multicolumn{5}{|l|}{ Types of admission } \\
\hline Non-elective & Reference & & & \\
\hline Elective & 0.95 (0.83 to 1.08$)$ & 0.397 & & \\
\hline Others & 0.85 (0.24 to 3.03$)$ & 0.802 & & \\
\hline Length of hospital stay & 1.13 (1.12 to 1.14$)$ & $<0.001$ & 1.13 (1.12 to 1.15$)$ & $<0.001$ \\
\hline \multicolumn{5}{|l|}{ Hyperlipidaemia } \\
\hline No & Reference & & Reference & \\
\hline Yes & 0.77 (0.67 to 0.89$)$ & $<0.001$ & 0.97 (0.83 to 1.12 ) & 0.671 \\
\hline \multicolumn{5}{|l|}{ Obesity } \\
\hline No & Reference & & & \\
\hline Yes & 1.09 (0.91 to 1.30$)$ & 0.353 & & \\
\hline
\end{tabular}

$\mathrm{P}<0.05$ is shown in bold.

\section{DISCUSSION}

This study investigated factors significantly associated with the risk of postoperative complications and in-hospital mortality in patients with CRC with coexisting CLD who underwent colorectal surgery. Our data showed that $20.84 \%$ of our study population comprised patients with CLD. Patients with CLD had a significantly longer duration of hospital stay compared with patients without CLD. Patients with postoperative infection, postoperative bleeding, respiratory complications and digestive complications had a significantly longer hospital stay compared with patients without postoperative complications. The presence of CLD was significantly associated with a higher risk of postoperative bleeding and a lower risk of respiratory complications. The presence of CLD and duration of hospital stay were significantly associated with a higher risk of in-hospital mortality, whereas the presence of hyperlipidaemia was associated with a lower risk of in-hospital mortality.

Data for this study were extracted from the HCUP-NIS database, which is the largest publicly available collection of longitudinal hospital care clinical data in the USA beginning in 1988. We were, therefore, able to perform analysis of trends over time and make national estimates 
Table 3A Univariate logistic regression analyses to identify risk factors for specific postoperative complications among inpatients diagnosed with colorectal cancer

\begin{tabular}{|c|c|c|c|c|c|c|}
\hline & \multicolumn{2}{|c|}{ Postoperative infection } & \multicolumn{2}{|c|}{ Postoperative bleeding } & \multicolumn{2}{|c|}{ Cardiac arrest/heart failure } \\
\hline & OR $(95 \% \mathrm{Cl})$ & $P$ values & OR $(95 \% \mathrm{Cl})$ & $P$ values & OR $(95 \% \mathrm{Cl})$ & $P$ values \\
\hline \multicolumn{7}{|l|}{ Chronic liver diseases } \\
\hline Yes & 1.16 (0.90 to 1.49$)$ & 0.255 & 1.67 (1.17 to 2.38$)$ & 0.005 & $0.82(0.51$ to 1.31$)$ & 0.404 \\
\hline \multicolumn{7}{|l|}{ Race } \\
\hline Black & 0.93 (0.64 to 1.35$)$ & 0.691 & $0.72(0.38$ to 1.34$)$ & 0.301 & $0.86(0.43$ to 1.72$)$ & 0.664 \\
\hline Hispanic & 1.30 (0.81 to 2.08$)$ & 0.273 & $0.94(0.43$ to 2.06$)$ & 0.867 & $1.39(0.62$ to 3.11$)$ & 0.428 \\
\hline Asian or Pacific islander & 0.96 (0.43 to 2.16$)$ & 0.924 & 0.32 (0.04 to 2.39$)$ & 0.265 & 1.95 (0.55 to 6.92$)$ & 0.301 \\
\hline Native American & 2.65 (0.66 to 10.63$)$ & 0.169 & NA & NA & $1.68(0.20$ to 13.93$)$ & 0.630 \\
\hline Other/Missing & 0.93 (0.70 to 1.25$)$ & 0.636 & $0.96(0.62$ to 1.48$)$ & 0.858 & 0.79 (0.48 to 1.29$)$ & 0.314 \\
\hline Quartile 3 & 0.94 (0.69 to 1.28$)$ & 0.691 & $0.74(0.44$ to 1.25$)$ & 0.260 & $1.40(0.81$ to 2.43$)$ & 0.225 \\
\hline Quartile 4 & 0.78 (0.56 to 1.09$)$ & 0.141 & 0.87 (0.52 to 1.45$)$ & 0.597 & $1.23(0.70$ to 2.16$)$ & 0.479 \\
\hline Others & 0.73 (0.30 to 1.76$)$ & 0.488 & $0.92(0.26$ to 3.21$)$ & 0.898 & 1.82 (0.59 to 5.57$)$ & 0.296 \\
\hline \multicolumn{7}{|l|}{ Location of hospital } \\
\hline Rural & Reference & & Reference & & Reference & \\
\hline Urban non-teaching & $1.23(0.82$ to 1.84$)$ & 0.320 & 0.94 (0.53 to 1.67$)$ & 0.833 & 1.04 (0.57 to 1.90$)$ & 0.888 \\
\hline Urban teaching & 1.45 (0.99 to 2.14$)$ & 0.058 & $1.06(0.61$ to 1.84$)$ & 0.828 & 1.08 (0.60 to 1.96$)$ & 0.797 \\
\hline Others & 0.52 (0.07 to 4.07 ) & 0.536 & NA & NA & 3.16 (0.60 to 16.64$)$ & 0.175 \\
\hline \multicolumn{7}{|l|}{ Types of admission } \\
\hline No & Reference & & Reference & & Reference & \\
\hline Yes & $0.64(0.48$ to 0.85$)$ & 0.002 & 0.88 (0.59 to 1.32$)$ & 0.544 & 0.75 (0.49 to 1.15$)$ & 0.191 \\
\hline \multicolumn{7}{|l|}{ Obesity } \\
\hline No & Reference & & Reference & & Reference & \\
\hline Yes & 1.30 (0.95 to 1.78$)$ & 0.098 & 0.69 (0.38 to 1.25$)$ & 0.218 & 1.12 (0.62 to 2.02$)$ & 0.709 \\
\hline
\end{tabular}

$\mathrm{P}<0.05$ is shown in bold.

NA, not available.

of healthcare utilisation, access, charges, quality and outcomes. The NIS sampling frame has grown from 8 states in 1988, to 22 states in 1998, to 46 states in 2011, and currently covers $97 \%$ of the US population.

Studies evaluating operative risk in patients with liver disease found that operative risk was correlated with severity of the underlying liver disease and nature of the surgical procedure. The increased perioperative risk among patients with underlying liver disease could be due to impairment of hepatic functions such as drug metabolism, detoxification of endogenous or exogenous toxins, and production of plasma proteins. ${ }^{10}$ Assessment of Child-Pugh classification and the Model for End-Stage Liver Disease score, in combination with careful preoperative and postoperative monitoring, has been shown to be crucial for improving outcomes. ${ }^{1018} 19$ Additionally, some investigators have described the development of risk indices to distinguish low-risk and high-risk subgroups for predicting postoperative mortality in patients with cirrhosis and CRC. ${ }^{14} 20$

Patients with CLD who undergo CRC surgery have previously been shown to have a significantly higher risk of postoperative mortality compared with patients without CLD. ${ }^{14} 21-23$ Data from a previous population-based study 
Table 3B Univariate logistic regression analyses to identify risk factors for specific postoperative complications among inpatients diagnosed with colorectal cancer

\begin{tabular}{|c|c|c|c|c|}
\hline & \multicolumn{2}{|c|}{ Respiratory complications } & \multicolumn{2}{|c|}{ Digestive system complications } \\
\hline & OR (95\% Cl) & $P$ values & OR $(95 \% \mathrm{Cl})$ & $P$ values \\
\hline \multicolumn{5}{|l|}{ Chronic liver diseases } \\
\hline No & Reference & & Reference & \\
\hline Yes & $0.62(0.38$ to 1.00$)$ & 0.048 & 1.04 (0.86 to 1.26$)$ & 0.697 \\
\hline \multicolumn{5}{|l|}{ Race } \\
\hline White & Reference & & Reference & \\
\hline Black & $0.60(0.30$ to 1.18$)$ & 0.139 & 1.32 (1.02 to 1.72$)$ & 0.034 \\
\hline Hispanic & $0.61(0.23$ to 1.59$)$ & 0.312 & 0.70 (0.45 to 1.08$)$ & 0.106 \\
\hline Asian or Pacific islander & NA & NA & 1.14 (0.63 to 2.08$)$ & 0.668 \\
\hline Native American & NA & NA & 0.47 (0.06 to 3.67$)$ & 0.474 \\
\hline Other/Missing & $1.06(0.69$ to 1.63$)$ & 0.776 & 0.99 (0.81 to 1.23$)$ & 0.957 \\
\hline \multicolumn{5}{|l|}{ Median household income } \\
\hline Quartile 1 & Reference & & Reference & \\
\hline Quartile 2 & $1.15(0.71$ to 1.86$)$ & 0.577 & 1.05 (0.83 to 1.32$)$ & 0.706 \\
\hline Quartile 3 & 0.84 (0.50 to 1.39$)$ & 0.492 & 1.00 (0.78 to 1.27$)$ & 0.990 \\
\hline Quartile 4 & 1.05 (0.63 to 1.74$)$ & 0.857 & 1.21 (0.96 to 1.54$)$ & 0.112 \\
\hline Others & $0.96(0.27$ to 3.44$)$ & 0.953 & 1.24 (0.71 to 2.18$)$ & 0.454 \\
\hline \multicolumn{5}{|l|}{ Location of hospital } \\
\hline Rural & Reference & & Reference & \\
\hline Urban non-teaching & 0.91 (0.55 to 1.48$)$ & 0.694 & 1.08 (0.82 to 1.40$)$ & 0.588 \\
\hline Urban teaching & $0.46(0.27$ to 0.76$)$ & 0.003 & 0.95 (0.73 to 1.24$)$ & 0.710 \\
\hline Others & NA & NA & 2.16 (0.82 to 5.69$)$ & 0.120 \\
\hline \multicolumn{5}{|l|}{ Types of admission } \\
\hline Non-elective & Reference & & Reference & \\
\hline Elective & $1.06(0.72$ to 1.56$)$ & 0.777 & 1.01 (0.84 to 1.22$)$ & 0.879 \\
\hline Others & NA & NA & 0.98 (0.21 to 4.46$)$ & 0.977 \\
\hline Length of hospital stay & 1.04 (1.02 to 1.06$)$ & 0.001 & 1.05 (1.04 to 1.06$)$ & $<0.001$ \\
\hline \multicolumn{5}{|l|}{ Hyperlipidaemia } \\
\hline No & Reference & & Reference & \\
\hline Yes & 0.74 (0.48 to 1.15$)$ & 0.183 & 1.01 (0.83 to 1.22$)$ & 0.948 \\
\hline \multicolumn{5}{|l|}{ Obesity } \\
\hline No & Reference & & Reference & \\
\hline Yes & 1.24 (0.72 to 2.14$)$ & 0.441 & 1.14 (0.88 to 1.48$)$ & 0.328 \\
\hline
\end{tabular}

$\mathrm{P}<0.05$ is shown in bold.

NA, not available.

showed that patients with CLD had a 6.5-fold higher risk of mortality after colorectal surgery, as well as significantly higher rates of postoperative complications compared with non-CLD patients. ${ }^{24}$ These data were consistent with our results, which showed that the presence of CLD was associated with a higher risk of in-hospital mortality, and suggested that identification of risk factors associated with postoperative complications and mortality in these patients could be critical to improving the clinical outcome.

Our data showed that patients with CRC with CLD had a significantly longer hospital stay compared with patients without CLD. This could possibly be due to a higher rate of specific postoperative complications. This was evident in our multivariate regression analysis, which showed that the presence of CLD was associated with a higher risk of postoperative bleeding. Although our data showed that the presence of CLD was associated with a lower risk of respiratory complications, we only evaluated surgery-related respiratory complications, and not the most common CLD-related pulmonary complications such as hepatopulmonary syndrome, portopulmonary hypertension and hepatic hydrothorax. ${ }^{25}$ We also analysed the correlation between length of hospital stay and incidence 


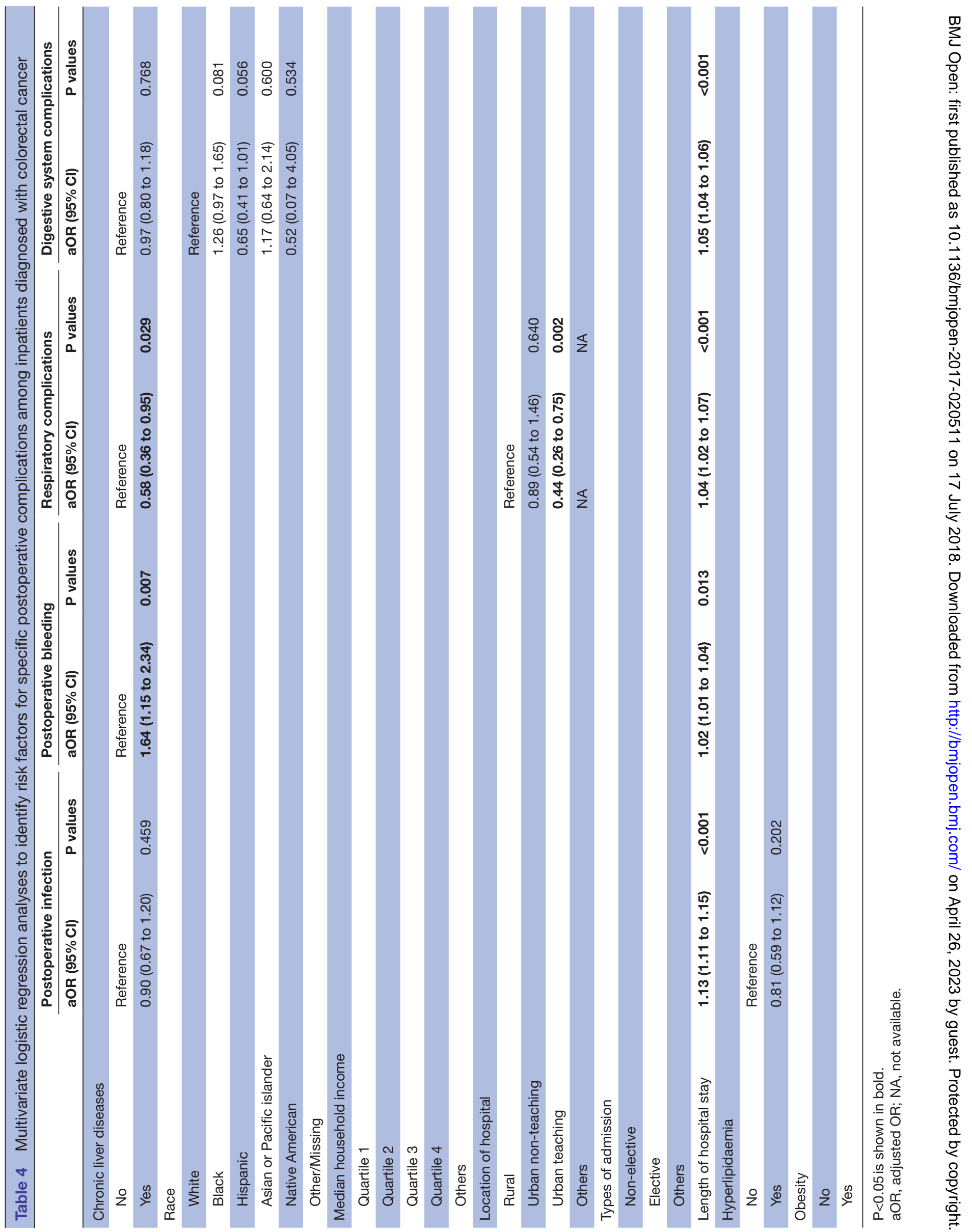


Table 5 Univariate and multivariate logistic regression analyses to identify factors associated with in-hospital mortality among inpatients diagnosed with colorectal cancer.

\begin{tabular}{|c|c|c|c|c|}
\hline & \multicolumn{2}{|l|}{ Univariate } & \multicolumn{2}{|l|}{ Multivariate } \\
\hline & OR $(95 \% \mathrm{Cl})$ & $P$ values & aOR $(95 \% \mathrm{Cl})$ & $P$ values \\
\hline \multicolumn{5}{|l|}{ Chronic liver diseases } \\
\hline No & Reference & & Reference & \\
\hline Yes & 2.33 (1.68 to 3.23$)$ & $<0.001$ & 2.05 (1.43 to 2.94$)$ & $<0.001$ \\
\hline \multicolumn{5}{|l|}{ Race } \\
\hline White & Reference & & & \\
\hline Black & 1.31 (0.76 to 2.27$)$ & 0.332 & & \\
\hline Hispanic & 0.93 (0.42 to 2.06) & 0.864 & & \\
\hline Asian or Pacific Islander & NA & NA & & \\
\hline Native American & NA & NA & & \\
\hline Other/Missing & 0.86 (0.55 to 1.35$)$ & 0.512 & & \\
\hline \multicolumn{5}{|l|}{ Median household income } \\
\hline Quartile 1 & Reference & & Reference & \\
\hline Quartile 2 & 1.28 (0.83 to 1.96$)$ & 0.268 & 1.51 (0.95 to 2.40$)$ & 0.083 \\
\hline Quartile 3 & $0.58(0.35$ to 0.99$)$ & 0.046 & 0.71 (0.41 to 1.26$)$ & 0.247 \\
\hline Quartile 4 & $0.68(0.40$ to 1.15$)$ & 0.152 & 0.77 (0.42 to 1.39) & 0.384 \\
\hline Others & 1.72 (0.59 to 4.96$)$ & 0.32 & 1.17 (0.35 to 3.83$)$ & 0.8 \\
\hline \multicolumn{5}{|l|}{ Location of hospital } \\
\hline Rural & Reference & & Reference & \\
\hline Urban non-teaching & 0.65 (0.40 to 1.04$)$ & 0.073 & 0.63 (0.37 to 1.08$)$ & 0.094 \\
\hline Urban teaching & 0.59 (0.37 to 0.94$)$ & 0.025 & 0.63 (0.37 to 1.06$)$ & 0.084 \\
\hline Others & 2.87 (0.29 to 28.13 ) & 0.365 & 4.54 (0.43 to 48.16$)$ & 0.209 \\
\hline \multicolumn{5}{|l|}{ Types of admission } \\
\hline Non-elective & Reference & & Reference & \\
\hline Elective & 0.37 (0.26 to 0.52$)$ & $<0.001$ & 0.50 (0.34 to 0.73$)$ & $<0.001$ \\
\hline Others & NA & NA & NA & NA \\
\hline Length of hospital stay & 1.07 (1.05 to 1.09$)$ & $<0.001$ & 1.06 (1.04 to 1.08$)$ & $<0.001$ \\
\hline \multicolumn{5}{|l|}{ Hyperlipidaemia } \\
\hline No & Reference & & Reference & \\
\hline Yes & $0.39(0.25$ to 0.63$)$ & $<0.001$ & $0.46(0.28$ to 0.75$)$ & 0.002 \\
\hline \multicolumn{5}{|l|}{ Obesity } \\
\hline No & Reference & & & \\
\hline Yes & 0.56 (0.29 to 1.08$)$ & 0.084 & & \\
\hline
\end{tabular}

$\mathrm{P}<0.05$ is shown in bold.

aOR, adjusted OR; NA, not applicable.

of postoperative complications. Our data indicated that patients with postoperative complications (including postoperative infection, postoperative bleeding, cardiac arrest/heart failure, respiratory complications and digestive complications) had a significantly longer duration of hospital stay compared with patients without postoperative complications.

The majority of patients with CLD in our study had chronic hepatitis C infection, followed by NAFLD. Our data were consistent with previous studies showing that patients with chronic hepatitis $\mathrm{C}$ and NAFLD had a significantly higher incidence of colorectal adenomas and advanced neoplasms compared with healthy controls. ${ }^{162627}$

Previous results showed that although mortality rates were higher in patients who were emergently admitted compared with patients with elective admission, there was no significant difference in the adjusted relative risk of mortality between the two groups. ${ }^{13}$ Our data showed that the type of admission (emergent vs elective) was not significantly associated with the risk of postoperative complications, but was associated with the risk of 
Table 6 Difference between postoperative complications and length of hospital stay in patients with colorectal cancer with chronic liver disease $(n=1555)$

\begin{tabular}{|c|c|c|}
\hline & \multicolumn{2}{|c|}{ Length of hospital stay } \\
\hline & Median (IQR) & $P$ values \\
\hline \multicolumn{2}{|l|}{ Postoperative complications } & $<0.001$ \\
\hline No & $7.0(5.0-10.0)$ & \\
\hline Yes & $11.5(5.0-10.0)$ & \\
\hline \multicolumn{2}{|l|}{ Postoperative infection } & $<0.001$ \\
\hline No & $7.0(5.0-10.0)$ & \\
\hline Yes & $17.0(10.0-26.0)$ & \\
\hline \multicolumn{2}{|l|}{ Postoperative bleeding } & 0.009 \\
\hline No & $7.0(5.0-10.0)$ & \\
\hline Yes & $8.0(6.0-12.0)$ & \\
\hline \multicolumn{2}{|l|}{ Cardiac arrest/heart failure } & 0.047 \\
\hline No & $7.0(5.0-10.0)$ & \\
\hline Yes & $8.0(6.0-17.0)$ & \\
\hline \multicolumn{2}{|l|}{ Respiratory complications } & 0.007 \\
\hline No & $7.0(5.0-10.0)$ & \\
\hline Yes & $9.0(8.0-14.0)$ & \\
\hline \multicolumn{2}{|c|}{ Digestive system complications } & $<0.001$ \\
\hline No & $7.0(5.0-10.0)$ & \\
\hline Yes & $10.5(7.0-17.0)$ & \\
\hline
\end{tabular}

mortality among inpatients with CRC who had coexisting CLD.

It has been reported that a low SES was significantly associated with a high incidence of CRC, regardless of individual-level CRC risk factors. ${ }^{28}$ Our multivariate analysis showed that patients in quartile 2 of the median household income had a significantly higher risk of in-hospital mortality compared with patients in quartiles 3 and 4, suggesting that low SES was significantly associated with a higher risk of in-hospital mortality in patients with CRC with CLD. This could be a reflection of poorer access to and lower utilisation of healthcare services among patients with low SES.

Our data showed that hyperlipidaemia was associated with a significantly lower risk of postoperative in-hospital mortality. Hyperlipidaemia is known to be associated with increased risk of cardiovascular disease events and increased all-cause mortality. Our present findings could be due to the fact that patients with a diagnosis of hyperlipidaemia were prescribed statins and had a good compliance. Statin monotherapy has previously been shown to exert a protective effect and decrease the rate of colorectal cancer mortality. ${ }^{29}$ Statin use has been shown to be an independent predictor of longer cancer-specific survival and overall survival in patients with curatively resected CRC. ${ }^{30}$ Additionally, since the levels of adiponectin and leptin are significantly decreased and increased, respectively, in patients with NAFLD and CRC, ${ }^{31}{ }^{32}$ it will be interesting to evaluate whether changes in adiponectin/ leptin ratios in these patients are associated with clinical outcomes.

Based on our data source, the major strengths of our study are (1) the sample size which is large enough to determine fairly precise prevalence measures at the national level, (2) the large multiethnic population sample which allowed us to explore racial/ethnic heterogeneity, and (3) the analysis which was conducted in a nationally representative sample and therefore the results may be generalised to the entire US adult population. The following were the major limitations of this study: (1) This was a cross-sectional analysis, and the unit of this database was the individual medical record. Our study, therefore, could not make any inferences regarding causality. (2) It is possible that the number of hospital discharges recorded could include an undetermined number of repeat hospital stays for the same patient. (3) The NIS is a US inpatient data (including representative proportions of people of different ethnicity) and should be validated in other countries. (4) Our study used the ICD-9 codes to characterise the disease, comorbidities and interventions. Validation of ICD-9 codes using parameters such as patient charts or a combination of patient claims along with part B Medicare claims is important during the course of epidemiological studies performed using administrative databases such as Surveillance, Epidemiology and End Results Program (SEER). ${ }^{33} 34$ To the best of our knowledge, this is the first population-based, cross-sectional study of hospitalised patients evaluating the factors associated with postoperative complications and mortality in patients with CRC with coexisting CLD.

\section{CONCLUSION}

Our study showed that postoperative infection, postoperative bleeding, respiratory complications and digestive complications all significantly prolonged the duration of hospital stay among patients with CRC with underlying CLD. The presence of CLD was significantly associated with a higher risk of postoperative bleeding and a lower risk of respiratory complications. Our data suggested that postoperative bleeding should be closely monitored in patients with CRC with CLD, since it may result in a higher risk of in-hospital mortality in these patients. The presence of CLD and duration of hospital stay were significantly associated with a higher risk of in-hospital mortality, whereas the presence of hyperlipidaemia was a protective factor.

Identification of factors associated with perioperative or postoperative complications and mortality in patients with CRC with underlying CLD can help to improve clinical management and outcomes in this group of patients with CRC.

Contributors K-CL: conception and design; acquisition of data; analysis and interpretation of data; drafting of the manuscript; critical revision of the manuscript; guarantor of integrity of the entire study; definition of intellectual content; administrative, technical or material support; supervision. K-CChu: conception and design; acquisition of data; analysis and interpretation of data; drafting of 
the manuscript; critical revision of the manuscript; guarantor of integrity of the entire study; definition of intellectual content; administrative, technical or material support; supervision. H-HC: acquisition of data; analysis and interpretation of data; critical revision of the manuscript; statistical analysis; administrative, technical or material support. K-CChe: analysis and interpretation of data; critical revision of the manuscript; statistical analysis; clinical studies. K-LW: analysis and interpretation of data; critical revision of the manuscript; statistical analysis; clinical studies. C-CL: analysis and interpretation of data; critical revision of the manuscript; literature research; clinical studies. All authors have read and approved the submitted version.

Funding The authors have not declared a specific grant for this research from any funding agency in the public, commercial or not-for-profit sectors.

Competing interests None declared.

Patient consent Not required.

Ethics approval Analysis of the data does not require IRB approval or informed consent from all subjects.

Provenance and peer review Not commissioned; externally peer reviewed.

Data sharing statement All data can be accessed from the National Inpatient Sample Database. NIS releases for data years 1988 through 2015 are available for purchase online through the online HCUP Central Distributor. All HCUP data users, including data purchasers and collaborators, must complete the online HCUP Data Use Agreement Training Tool, and must read and sign the Data Use Agreement for Nationwide Databases. Questions about purchasing databases can be directed to the HCUP Central Distributor: email: HCUPDistributor@AHRQ.gov, tel: (866) 5564287 (toll free), fax: (866) 792-5313 (toll free).

Open access This is an open access article distributed in accordance with the Creative Commons Attribution Non Commercial (CC BY-NC 4.0) license, which permits others to distribute, remix, adapt, build upon this work non-commercially, and license their derivative works on different terms, provided the original work is properly cited, appropriate credit is given, any changes made indicated, and the use is non-commercial. See: http://creativecommons.org/licenses/by-nc/4.0/.

\section{REFERENCES}

1. Siegel R, Naishadham D, Jemal A. Cancer statistics, 2012. CA Cancer J Clin 2012;62:10-29.

2. Jemal A, Bray F, Center MM, et al. Global cancer statistics. $C A$ Cancer J Clin 2011;61:69-90.

3. Jemal A, Clegg LX, Ward E, et al. Annual report to the nation on the status of cancer, 1975-2001, with a special feature regarding survival. Cancer 2004;101:3-27.

4. Haggar FA, Boushey RP. Colorectal cancer epidemiology: incidence, mortality, survival, and risk factors. Clin Colon Rectal Surg 2009;22:191-7.

5. Noel MS. Biologics in bowel cancer. J Gastrointest Oncol 2017;8:449-56.

6. Fernández-Iglesias A, Gracia-Sancho J. How to Face Chronic Liver Disease: The Sinusoidal Perspective. Front Med 2017;4:7.

7. Friedman SL. Mechanisms of hepatic fibrogenesis. Gastroenterology 2008;134:1655-69.

8. Goyal NP, Schwimmer JB. The Progression and Natural History of Pediatric Nonalcoholic Fatty Liver Disease. Clin Liver Dis 2016;20:325-38.

9. Aranha GV, Sontag SJ, Greenlee HB. Cholecystectomy in cirrhotic patients: a formidable operation. Am J Surg 1982;143:55-60.

10. Hanje AJ, Patel T. Preoperative evaluation of patients with liver disease. Nat Clin Pract Gastroenterol Hepatol 2007;4:266-76.
11. Friedman LS. The risk of surgery in patients with liver disease. Hepatology 1999;29:1617-23.

12. Komaki Y, Komaki F, Micic D, et al. Risk of colorectal cancer in chronic liver diseases: a systematic review and meta-analysis. Gastrointest Endosc 2017;86:93-104.

13. Montomoli J, Erichsen R, Christiansen CF, et al. Liver disease and 30-day mortality after colorectal cancer surgery: a Danish population-based cohort study. BMC Gastroenterol 2013;13:66.

14. Metcalf AM, Dozois RR, Wolff BG, et al. The surgical risk of colectomy in patients with cirrhosis. Dis Colon Rectum 1987;30:529-31.

15. Schwartz SI. Biliary tract surgery and cirrhosis: a critical combination. Surgery 1981;90:577-83.

16. Sørensen HT, Mellemkjaer L, Jepsen P, et al. Risk of cancer in patients hospitalized with fatty liver: a Danish cohort study. J Clin Gastroenterol 2003;36:356-9.

17. You J, Huang S, Huang GQ, et al. Nonalcoholic fatty liver disease: a negative risk factor for colorectal cancer prognosis. Medicine 2015;94:e479.

18. Friedman LS. Surgery in the patient with liver disease. Trans Am Clin Climatol Assoc 2010;121:192-204. discussion 5.

19. Patel T. Surgery in the patient with liver disease. Mayo Clin Proc 1999;74:593-9.

20. Hippisley-Cox J, Coupland C. Development and validation of risk prediction equations to estimate survival in patients with colorectal cancer: cohort study. BMJ 2017;357:j2497.

21. Gervaz P, Pak-art R, Nivatvongs S, et al. Colorectal adenocarcinoma in cirrhotic patients. J Am Coll Surg 2003;196:874-9.

22. Meunier K, Mucci S, Quentin V, et al. Colorectal surgery in cirrhotic patients: assessment of operative morbidity and mortality. Dis Colon Rectum 2008;51:1225-31.

23. Nguyen GC, Correia AJ, Thuluvath PJ. The impact of cirrhosis and portal hypertension on mortality following colorectal surgery: a nationwide, population-based study. Dis Colon Rectum 2009;52:1367-74.

24. Ghaferi AA, Mathur AK, Sonnenday CJ, et al. Adverse outcomes in patients with chronic liver disease undergoing colorectal surgery. Ann Surg 2010;252:345-50.

25. Surani SR, Mendez $\mathrm{Y}$, Anjum $\mathrm{H}$, et al. Pulmonary complications of hepatic diseases. World J Gastroenterol 2016;22:6008-15.

26. Rustagi T, Zarookian El, Qasba O, et al. Chronic hepatitis $\mathrm{C}$ as a risk factor for colorectal adenoma. Int J Colorectal Dis 2014;29:75-80.

27. Wong VW, Wong GL, Tsang SW, et al. High prevalence of colorectal neoplasm in patients with non-alcoholic steatohepatitis. Gut 2011;60:829-36.

28. Doubeni CA, Laiyemo AO, Major JM, et al. Socioeconomic status and the risk of colorectal cancer: an analysis of more than a half million adults in the National Institutes of Health-AARP Diet and Health Study. Cancer 2012;118:3636-44.

29. Yokomichi $\mathrm{H}$, Nagai A, Hirata M, et al. Statin use and all-cause and cancer mortality: BioBank Japan cohort. J Epidemiol 2017;27:S84-S91.

30. Shao YY, Hsu CH, Yeh KH, et al. Statin Use Is Associated With Improved Prognosis of Colorectal Cancer in Taiwan. Clin Colorectal Cancer 2015;14:177-84.

31. Ferroni P, Palmirotta R, Spila A, et al. Prognostic significance of adiponectin levels in non-metastatic colorectal cancer. Anticancer Res 2007;27:483-9.

32. Guadagni F, Roselli M, Martini F, et al. Prognostic significance of serum adipokine levels in colorectal cancer patients. Anticancer Res 2009;29:3321-7.

33. Abraha I, Giovannini G, Serraino D, et al. Validity of breast, lung and colorectal cancer diagnoses in administrative databases: a systematic review protocol. BMJ Open 2016;6:e010409.

34. Cooper GS, Yuan Z, Stange KC, et al. The sensitivity of Medicare claims data for case ascertainment of six common cancers. Med Care 1999;37:436-44. 